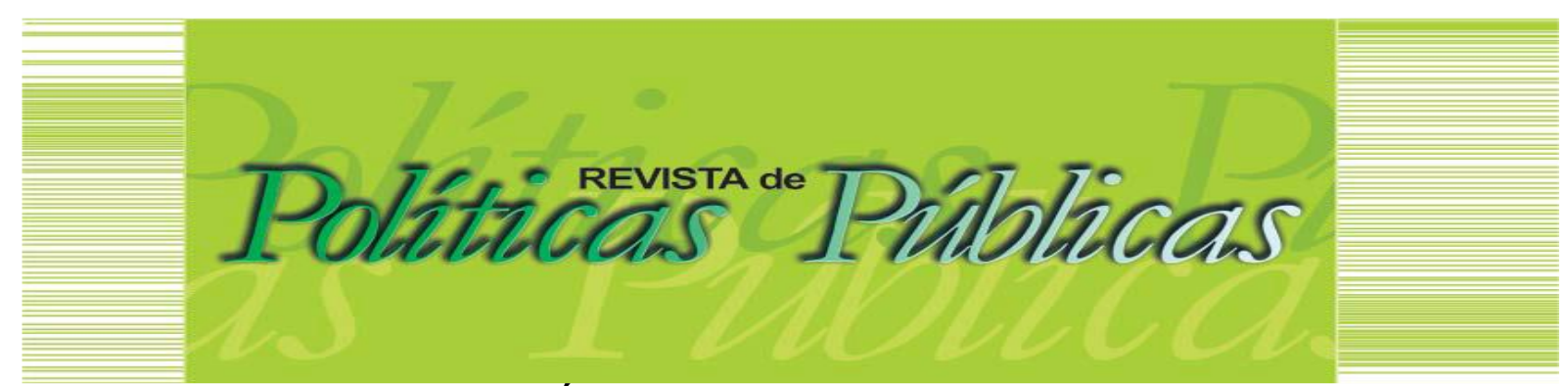

O CIGARRO E A SAÚDE: instruir positivamente ou provocar o medo?

\author{
Lorenna Glenda Medeiros Dias 1 \\ Rejane Alexandrina Domingues Pereira do Prado² \\ Marli Auxiliadora da Silva ${ }^{3}$ \\ Jussara Goulart da Silva 4 \\ Edson Arlindo Silva ${ }^{5}$ \\ Tayná Mendonça Sobottka 6
}

\begin{abstract}
Resumo
A Constituição Federal de 1988 trouxe modificações significativas na arquitetura e no funcionamento do Estado, possibilitando a criação de novas estratégias para viabilizar a formulação e a implementação de políticas públicas no Brasil. Contextualmente, pode-se dizer que 0 setor de saúde serve de modelo às práticas participativas de decisões compartilhadas e teve um papel importante no exercício do controle social, permitindo o protagonismo da sociedade civil organizada nos mais diversos espaços públicos, o que inclui decisões sobre políticas setoriais de prevenção e de combate ao tabagismo. Nesse sentido, o objetivo deste estudo foi verificar a influência das advertências sanitárias com framing positivo e negativo nas embalagens dos cigarros na intenção de parar de fumar e na emoção (culpa e vergonha) dos fumantes sob a ótica da Teoria do Foco Regulatório em um contexto de Marketing Social. $O$ estudo experimental possui o desenho fatorial $2 \times 2$, sendo duas advertências (apelo ao medo versus positiva) e dois focos regulatórios (promocional versus preventivo). Os resultados demonstraram que, apesar de os apelos de mídia não terem tido o efeito esperado, os fumantes com perfil promocional tendem a ter uma maior intenção de parar de fumar do que os fumantes preventivos. Os resultados contribuem com a temática, pois ainda não há consenso quanto à influência de mensagens dessa natureza na intenção de uso dos fumantes, colaborando também com insumos para os formuladores de políticas públicas. As conclusões relevantes deste estudo, no que tange ao framing positivo e negativo, apontam que a relação entre esses dois polos pode ser justificada pelo fato de o uso da nicotina gerar vício e, por isso, o fumante pode necessitar de tratamento médico para conseguir parar de fumar e não apenas de uma comunicação persuasiva.
\end{abstract}

Palavras-chave: Tabagismo. Políticas Públicas. Teoria do Foco Regulatório. Framing positivo e negativo. Marketing Social.

\footnotetext{
${ }^{1}$ Administradora. Curso de Graduação em Administração da Universidade Federal de Uberlândia (UFU)/Campus Pontal. Email: lorenna.medeirosdias@hotmail.com

2 Administradora. Doutora em Administração. Professora do Curso de Graduação em Administração da Universidade Federal de Uberlândia (UFU)/Campus Pontal. E-mail: rejane.prado@ufu.br

${ }^{3}$ Contadora. Doutora em Educação. Professora no Programa de Pós Graduação em Ciências Contábeis e no Curso de Graduação em Ciências Contábeis da Universidade Federal de Uberlândia (UFU). E-mail: marli.silva@ufu.br

${ }^{4}$ Administradora. Doutora em Administração. Professora no Curso de Graduação em Administração e no Programa de PósGraduação em Administração da Universidade Federal de Uberlândia (UFU). E- mail: profadmjussara.ufu@gmail.com

${ }^{5}$ Administrador. Doutor em Administração. Professor no Curso de Graduação em Administração da Universidade Federal de Uberlândia - UFU/Campus Pontal e Professor do Programa de Pós-Graduação em Gestão Organizacional da Universidade Federal de Catalão (UFCAT). E-mail: edsonasilva@ufu.br

${ }^{6}$ Graduanda em Engenharia de Produção. Curso de Graduação em Engenharia de Produção da Universidade Estácio de Sá. E-mail: taatasobottka@gmail.com
} 


\title{
O CIGARRO E A SAÚDE: instruir positivamente ou provocar o medo?
}

\section{CIGARETTE AND HEALTH: instructing positively or provoking fear?}

\begin{abstract}
The Federal Constitution of 1988 brought significant changes in the architecture and functioning of the State, making possible the creation of new strategies to enable the formulation and implementation of public policies in Brazil. In this context, it can be said that the health sector serves as a model for the participative practices of shared decisions and played an important role in the exercise of social control, allowing the protagonism of the organized civil society in the most diverse public spaces, which includes decisions on sectoral policies to prevent and combat smoking. Thus, the objective of this study was to verify the influence of health warnings with positive and negative framing on cigarette packs in the intention to quit smoking and in the emotion (guilt and shame) of smokers from the perspective of the Regulatory Focus Theory in a context of Social Marketing. The experimental study presents a $2 \times 2$ factorial design: two warnings (appeal to fear versus positive) and two regulatory focuses (promotional versus preventive). The results have shown that although media appeals did not have the expected effect, smokers with a promotional profile tend to have a greater intention to quit smoking than preventive smokers. The results contribute to the theme, since there is still no consensus regarding the influence of messages of this nature on the use intention of smokers, also collaborating with inputs for public policy makers. The relevant conclusions of this study, regarding the positive and negative framing, point out that the relationship between these two poles can be justified by the fact that the use of nicotine causes addiction and, therefore, smokers may need medical treatment to be able to quit smoking and not only persuasive communication.
\end{abstract}

Keywords: Smoking. Public Policies. Regulatory Focus Theory. Positive and negative Framing. Social Marketing.

Artigo recebido em: 12/07/2020 Aprovado em: 12/05/2021 DOI: http://dx.doi.org/10.18764/2178-2865.v25n1p370-395 


\section{INTRODUÇÃO}

O tabagismo caracteriza-se pela dependência de nicotina causada pela inalação da fumaça resultante da combustão do tabaco contido nos cigarros, sendo considerado uma doença crônica que, em geral, inicia-se na adolescência (SILVA, 2012). Ademais, o tabagismo é apontado como uma pandemia pela Organização Mundial da Saúde (OMS) por levar a óbito, anualmente, cerca de sete milhões de pessoas no mundo, das quais 900 mil são fumantes passivos (inalam a fumaça do cigarro de fumantes ativos) (LABOISSIÈRE, 2018).

No ano de 2008, o Instituto Brasileiro de Geografia e Estatística (IBGE, 2008) estimou que, no Brasil, 24,6 milhões de pessoas, aproximadamente, de 15 anos de idade ou mais fumavam, 0 que corresponde a $17,2 \%$ de brasileiros nessa faixa etária. O IBGE informou também que $93,0 \%$ dos fumantes declararam conhecer as doenças graves que o cigarro pode causar e que $52,1 \%$ desses fumantes pensavam ou programavam não mais fumar (IBGE, 2008). No ano de 2014, por meio de nova pesquisa, o IBGE registrou que o número de fumantes no Brasil era de $14,7 \%$, dentre eles, os homens são os que mais fazem uso do cigarro, estando a faixa etária predominante de fumantes entre 40 a 59 anos (INCA, 2014a, 2014b).

Em 2015, cerca de um bilhão de pessoas no mundo inteiro fumavam diariamente, sendo um em quatro homens e uma, em vinte mulheres. No Brasil, entre 1990 e 2015, a porcentagem de fumantes diários reduziu de $29 \%$ para $12 \%$ entre homens e de $19 \%$ para $8 \%$ entre mulheres, mas, ainda assim, o país possui 7,1 milhões de mulheres e 11, 1 milhões de homens fumantes (BRASIL, 2017).

Apesar da redução do número de fumantes no Brasil, o percentual de usuários ainda é alto, por isso o Ministério da Saúde tem desenvolvido ações diversas para prevenir e controlar o tabagismo, tais como, atividades que influenciam o fumante a deixar de fumar, medidas preventivas nas escolas, desenvolvimento das políticas de controle e criação de leis cada vez mais restritivas. Essas ações tiveram início a partir de 1989, por meio do Programa Nacional de Controle do Tabagismo. $O$ declínio do número de fumantes e do consumo de cigarros demonstra que as atividades de controle realizadas até o momento são, de certa forma, eficazes (SILVA, 2012; BRASIL, 2017).

Outros fatores que podem ter contribuído para a redução no número de fumantes são: 0 acesso facilitado a medicamentos fornecidos pelo Ministério da Saúde; atendimento médico na rede pública de saúde para aqueles que desejam parar de fumar; a criação da Lei Antifumo (Lei $n^{0}$ 12.546/2011) decretada no governo Dilma Rousseff, em vigor desde dezembro de 2014, determinando 
que, em locais públicos fechados, haja $100 \%$ de restrição ao uso do tabaco, o que contribui para a redução do fumo passivo e diminuição da prática de tabagismo (INCA, 2014b).

Apesar dessas ações, 0 índice de fumantes ativos e passivos no Brasil ainda é preocupante. Assim, estudar as estratégias de combate ao fumo se faz necessário no sentido de criar bases para formulação de políticas públicas de combate ao uso do tabaco. Uma das estratégias que tem sido utilizada, não só no Brasil, mas em grande parte do mundo, é a inserção de advertências sanitárias nas embalagens de cigarro.

No ano de 1988, como registrado por Cavalcante (2005), no Brasil, foi inserido nas embalagens o primeiro aviso com a finalidade de advertir os fumantes sobre o risco do tabagismo: " 0 Ministério da Saúde adverte: Fumar faz mal à saúde", tendo sido, posteriormente, inseridas outras advertências. Nesse sentido, essa ação foi ganhando força com o passar dos anos, até que foram inseridas imagens de apelo ao medo nas embalagens de cigarro, advertindo sobre os malefícios causados pelo fumo, o que, segundo apontamentos do Ministério da Saúde, levou a uma redução do consumo desde então (CAVALCANTE, 2005; BRASIL, 2017).

Os números apresentados demonstram que as estratégias adotadas para combater o uso do fumo têm sido eficazes, pois o número de fumantes tem reduzido, no entanto, esse número ainda é alto, o que demonstra que medidas adicionais precisam ser adotadas. Nesse sentido, existem pesquisas no campo do neuromarketing que demonstram que as estratégias de apelo ao medo não funcionam para determinados perfis de consumidores, pois o fumante associa a imagem negativa utilizada nas advertências sanitárias ao prazer de fumar, uma vez que ele olha para a imagem, acende um cigarro, fuma e sente prazer. Fazendo isso repetidas vezes, ele cria uma associação entre a imagem de apelo ao medo e o prazer, o que torna essa imagem ineficiente quanto ao objetivo de fazer com que o fumante pare de fumar. (LINDSTROM, 2009).

Adicionalmente, pesquisas apontam que os fumantes afirmam que mensagens positivas, ou seja, aquelas que são otimistas, mostram o lado bom de não fumar, como as que destacam a importância de não fumar (principalmente, aquelas em que figuram famosos não fumantes), bem como as que enfatizam os benefícios de se ter uma vida saudável, seriam mais eficazes que mensagens com a utilização do apelo ao medo, as quais têm sido usadas pelo Ministério da Saúde nas embalagens dos cigarros no Brasil, mostrando um perfil distinto entre os consumidores de cigarro (MOTA et al., 2012).

Esse perfil divergente dos consumidores, ou seja, enquanto, para alguns, a mensagem de apelo ao medo pode funcionar, para outros, as mensagens não causam nenhuma influência, pode ser explicado pela Teoria do Foco Regulatório (TFR).

A TFR mostra um processo básico da busca de metas pelos consumidores e explica que 0 indivíduo tem seu comportamento de aproximação ou afastamento determinado em estratégias de 
autorregulação, que podem ser de dois tipos: a estratégia com Foco de Promoção e a estratégia com Foco de Prevenção (CROWE; HIGGINS, 1997; HIGGINS, 1997).

Consumidores preventivos tomam decisões diferentes de consumidores promocionais. Consumidores com um foco em promoção são mais sensiveis à ausência e à presença de emoções positivas, tais como, alegria, diversão, dentre outras, por isso, tais indivíduos são preocupados com o crescimento pessoal, com realizações e aspirações da vida (HIGGINS et al., 1994; HIGGINS, 1996, 1997; ALIYEV; WAGNER, 2018). Os consumidores com foco em prevenção são mais sensíveis com relação à carência e à presença de resultados negativos, tais como, medo, tristeza, entre outros, o que leva tais indivíduos a serem mais preocupados com segurança, responsabilidade e obrigações (HIGGINS et al., 1994; HIGGINS, 1996, 1997).

Diante do exposto, o presente estudo buscou responder ao seguinte questionamento: Qual a influência das advertências sanitárias (com mensagens positivas e de apelo ao medo) na intenção de parar de fumar e na emoção (culpa e vergonha) dos fumantes? Nesse sentido, o objetivo geral consiste em verificar a influência das advertências sanitárias com apelo ao medo presentes nas embalagens dos cigarros, bem como a influência das advertências sanitárias positivas na intenção de parar de fumar e na emoção (culpa e vergonha) dos fumantes.

Para o alcance do objetivo proposto, delineou-se uma pesquisa com a utilização do método experimental, pois tal método é o mais adequado para avaliar uma relação causal (MALHOTRA, 2006). Dessa forma, foi verificado o efeito das mensagens positivas e negativas (variáveis independentes) na intenção de compra e na emoção (variáveis dependentes) dos fumantes promocionais e preventivos (variáveis independentes). No total, 90 fumantes compuseram a amostra, sendo 30 em cada grupo amostral, conforme é detalhado nos procedimentos metodológicos. Os resultados obtidos neste estudo poderão contribuir com as investigações sobre a temática, visto que ainda não há, entre os pesquisadores, consenso quanto à influência de mensagens dessa natureza na intenção de uso ou de compra de cigarros pelos fumantes. Outrossim, os resultados poderão ser utilizados pelos formuladores de políticas públicas em campanhas antifumo e, quando pertinente, na definição de legislação específica.

O presente estudo está organizado em cinco seções, sendo esta primeira introdutória, seguida pelo referencial teórico, procedimentos metodológicos, resultados e discussões e, por fim, as considerações finais da pesquisa. 


\section{FUNDAMENTAÇÃO TEÓRICA}

Nesta seção, estão expostos alguns conceitos sobre o tabagismo e o uso de marketing social como uma das estratégias para esclarecer e alertar sobre o perigo causado pelo tabaco na saúde das pessoas com vistas à mudança de comportamento dos consumidores. Também, abordamse algumas discussões sobre o fumo, seus registros na história, o aumento de sua propagação e as advertências sanitárias brasileiras com foco na influência da comunicação, com destaque para os apelos de mídia: framing negativo e positivo, finalizando com a Teoria do Foco Regulatório (TFR).

\subsection{Tabagismo e marketing social}

$\mathrm{O}$ ato de fumar vem sendo praticado pela sociedade e registrado na história por mais de quinhentos anos, sendo uma das mais preocupantes pandemias já criadas pelo homem. Registros historiográficos apontam que sua propagação teve início em Cuba, onde os índios fumavam folhas em formato de rolos. Logo em seguida, o tabaco foi disseminado na Europa, em países como França, Espanha, Inglaterra e Portugal.

Inicialmente, o tabaco era considerado de grande poder medicinal, sendo utilizado para combater mais de 59 (cinquenta e nove) formas de doenças. Entretanto, seu uso medicinal foi perdendo espaço até desaparecer, mas o ato de fumar como sendo algo prazeroso continuou sendo difundido pelo mundo. A expansão do tabagismo se deu, principalmente, na primeira metade do Século XX devido à industrialização do cigarro e aumento das propagandas, passando 0 ato de fumar a ter valor de status, poder, beleza, charme, entre outros, e fazendo com que o cigarro se tornasse muito desejado por várias pessoas em todo o mundo (HORTENSE; CARMAGNANI; BRÊTAS, 2008).

$\mathrm{O}$ ato de fumar torna-se um vício, pois o cigarro contém nicotina, que é uma droga estimulante encontrada no tabaco que faz a frequência do pulso e a pressão sanguínea aumentarem. Entretanto, os fumantes defendem que fumar diminui quadros de aborrecimento e cansaço, além de acalmá-los quando estão tensos ou ansiosos (UNESP, 2012). Por outro lado, é comprovado cientificamente que o tabagismo provoca cerca de cinquenta doenças, sendo o principal responsável pelo desenvolvimento do câncer de pulmão, além de outros tipos de câncer, bem como doenças pulmonares crônicas, doenças coronarianas, doenças cerebrovasculares, entre outras. É oportuno ressaltar que, quando se abandona o hábito de fumar, a probabilidade de se desenvolver esses tipos de doenças diminui e o organismo se restabelece com o tempo (INCA, 2014a).

Dessa forma, na década de 50, em função dos males ocasionados pelo cigarro, governos de vários países começaram a desenvolver programas sociais com vistas a combater comportamentos 
não desejados socialmente, nesse caso, o hábito de fumar. Todavia, foi em 1971 que Kotler e Zaltman (1971) utilizaram a expressão Marketing Social, pela primeira vez, ao estudarem caminhos do marketing que contribuíssem para a pesquisa e alcance de resultados para vários problemas sociais.

0 marketing social foi descrito como o meio de gerar, estabelecer e supervisionar programas utilizados para motivar a adoção das ideias sociais, abrangendo observações referentes ao planejamento, preço, comunicação, distribuição e pesquisa de marketing (KOTLER; ZALTMAN, 1971). Andreasen $(1994,2002)$ também concorda que o marketing social tem como foco influenciar o modo de agir das pessoas, adaptando as tecnologias do marketing comercial a programas elaborados, trazendo melhorias para o bem-estar do indivíduo e, consequentemente, benefícios para a sociedade da qual ele participa.

Para a realização de um programa de marketing social, é necessário definir o objetivo com o emprego de várias ações para o alcance das metas. Nesse sentido, campanhas de combate ao fumo, que visam à mudança de comportamento, são realizadas no longo prazo por envolverem várias ações, como, por exemplo, a proibição das propagandas de cigarros, campanhas para não fumar em aviões e em ambientes públicos fechados e, também, advertências sanitárias nos rótulos de maços de cigarros (KOTLER; KELLER, 2006).

Em 1970 tiveram início, no Brasil, as ações contra o hábito de fumar, esclarecendo-se por meio de livros escritos e palestras os perigos referentes a esse hábito. A luta se tornou oficial em 1985 com a criação, pelo Ministério da Saúde, do Grupo Assessor do Ministério da Saúde para Controle do Tabagismo no Brasil (AMB, 2014). A própria Constituição Federal, em seu Artigo 220, e a Lei n. 9.294/1996 discorrem acerca das limitações à aplicação e à propaganda de produtos fumígeros, bebidas alcoólicas, medicamentos, terapias e defensivos agrícolas (BRASIL, 2014).

Assim, as ações de marketing social em relação ao cigarro no Brasil se deram, entre outras estratégias, por meio de mensagens de advertências sanitárias.

\subsection{Mensagens de advertências sanitárias nos maços de cigarros no Brasil}

As mensagens de advertências sanitárias presentes nos maços de cigarros fazem parte do rol dos Anúncios de Serviços Públicos (ASPs), sendo os APSs capazes de influenciar respostas positivas, bem como de promover a motivação de comportamentos pró-sociais (KIM, 2016). Esses anúncios, na maioria dos casos, utilizam como estratégia as emoções negativas, como tristeza, medo, tensão e culpa, as quais têm sido indicadas como um dos determinantes das respostas positivas dos indivíduos em relação aos ASPs, tanto em contextos de autoajuda quanto em se tratando de ajuda a 
terceiros (BAGOZZI; MOORE, 1994; COTTE; COULTER; MOORE, 2005; ANTONETTI; MAKLAN, 2014).

Mota et al. (2012) concordam que as campanhas sociais com foco no consumo do cigarro e suas consequências danosas são capazes de auxiliar na transformação de comportamentos e práticas do público fumante.

Em 1988, o governo brasileiro inseriu pela primeira vez, nas embalagens de cigarros, uma frase de advertência sobre o risco de fumar, qual seja, "O Ministério da Saúde adverte: Fumar faz mal à saúde". As campanhas foram crescendo a cada ano até que ocorreu a inserção de fotos nas embalagens de cigarro, advertindo sobre os malefícios causados pelo fumo (CAVALCANTE, 2005). Posteriormente, foi sancionada a Lei Antifumo, Lei n ${ }^{0}$. 12.546/2011, e todas essas ações, em conjunto, contribuíram para a redução do número de fumantes que, segundo o IBGE, era de $17,2 \%$ de brasileiros em 2008 e, em 2014, de 14,7\% (INCA, 2014b).

O Brasil foi o segundo país a inserir imagens nas embalagens de cigarro com a intenção de reduzir o número de fumantes, principalmente, entre jovens e adolescentes. Essas imagens utilizam o apelo ao medo como forma de alertar os indivíduos sobre os males ocasionados pelo cigarro. Advertências sanitárias ilustradas com imagens nas embalagens de cigarro são obrigatórias, mediante lei, desde 2001, tendo sido o Canadá o pioneiro na adoção de medidas que visam a impedir o aumento de fumantes jovens $(G 1,2008)$.

$\mathrm{Na}$ Figura 1, são apresentadas algumas imagens com advertências sanitárias utilizadas nas embalagens de cigarros comercializados no Brasil até 2017.

Figura 1 - Imagens antitabagismo utilizadas nas embalagens de cigarros até 2017
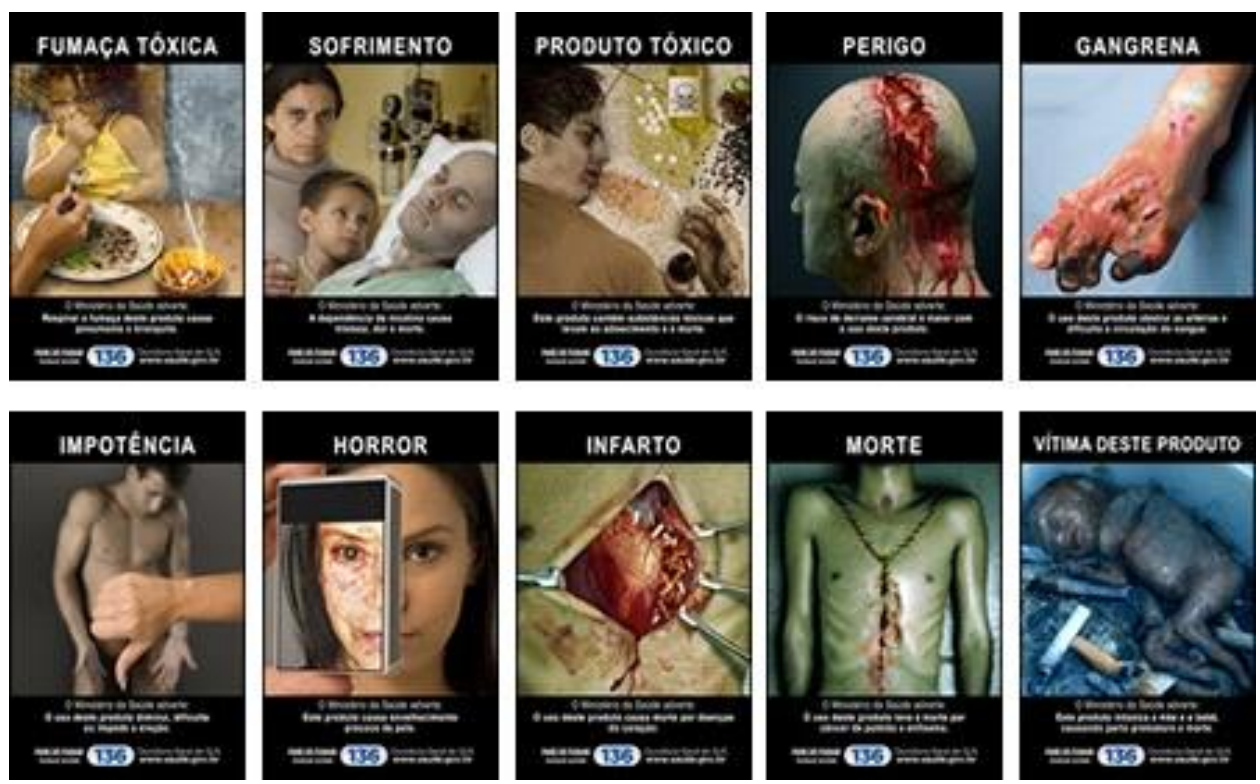

Fonte: ANVISA (2014). 
Em 2017, a Agência Nacional de Vigilância Sanitária (ANVISA) tornou pública a Resolução da Diretoria Colegiada 195/2017 com as novas imagens de advertências sanitárias obrigatórias a partir do dia 25 de maio de 2018. No total, são nove as novas imagens de advertências que ocupam cerca de $100 \%$ da parte posterior das embalagens (ANVISA, 2017).

As novas imagens e frases comunicam de forma mais direta com seus consumidores acerca dos problemas que esses produtos geram na saúde e, também, utilizam cores que dão maior ênfase e visibilidade às mensagens. As novas advertências relatam problemas como: câncer de boca, cegueira, envelhecimento, fumante passivo, impotência sexual, infarto, trombose e gangrena morte e parto prematuro, conforme ilustrado na Figura 2 (ANVISA, 2017).

Apesar da mudança, o foco da comunicação continuou sendo o apelo ao medo, não sendo inseridas mensagens/imagens com apelo positivo.

Figura 2 - Imagens antitabagismo usadas nas embalagens de cigarro a partir de 2018

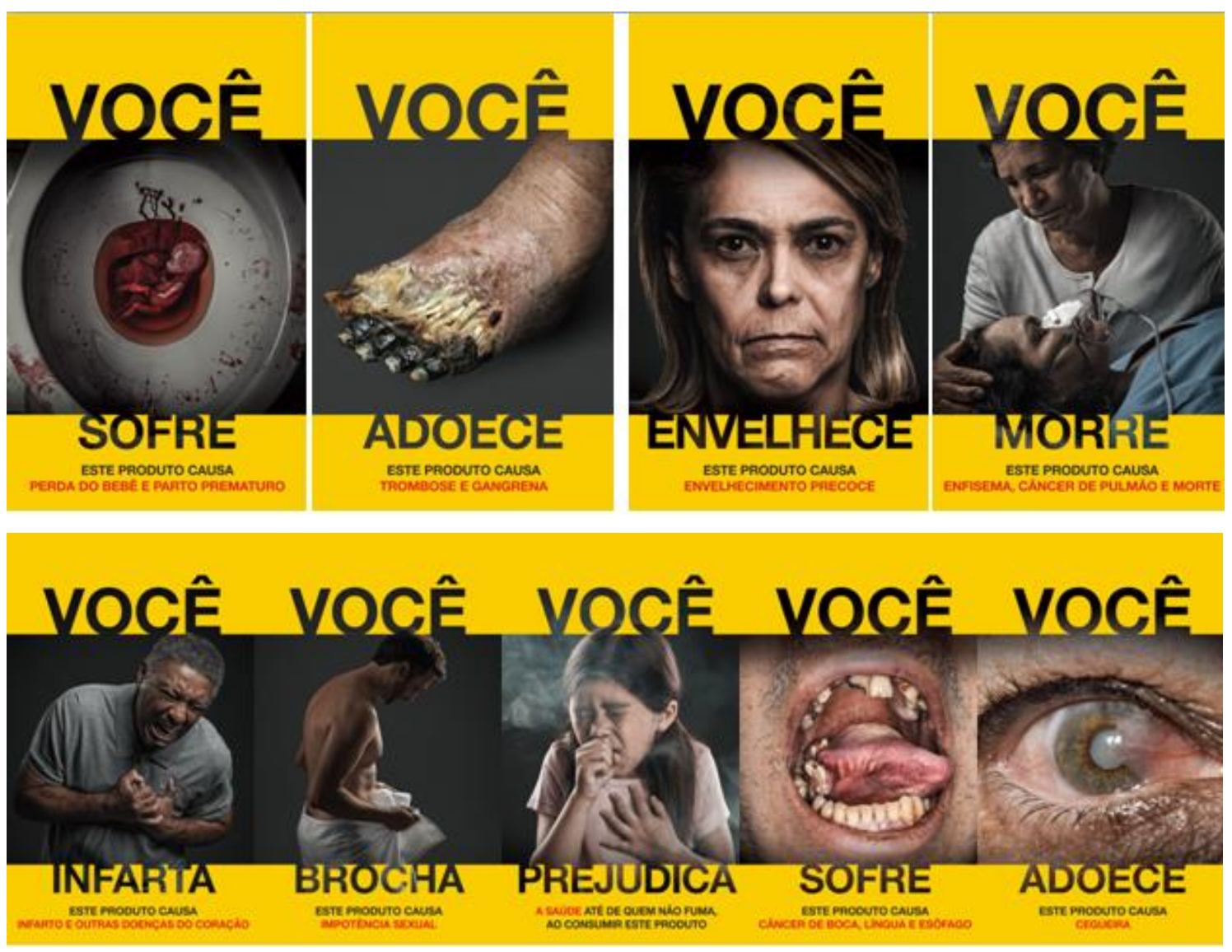

Fonte: ANVISA (2017).

Até o momento, as imagens e mensagens utilizadas nas embalagens de cigarros no Brasil se utilizam de apelo ao medo, estratégia de framing negativo. Entretanto, poderia ser utilizada, também, a estratégia de framing positivo, conforme será discutido na sequência. 
2.3 Apelos de mídia: framing negativo e positivo

Os apelos de mídia se diversificam cada dia mais na tentativa de persuadir os consumidores. Uma das teorias propostas nesse sentido é a Teoria dos Prospectos (KAHNEMAN; TVERSKY, 1979; TVERSKY; KAHNEMAN, 1981), por meio da qual os autores apontaram novas possibilidades de estudos comportamentais em diversas áreas. A partir desses estudos, pesquisas adicionais têm buscado determinar o impacto do comportamento sob o efeito framing. Por efeito framing, entende-se a possibilidade de influenciar a decisão de um indivíduo sem distorcer a informação, ou mesmo, suprimi-la, por meio de mudanças sutis na sua estruturação (TVERSKY; KAHNEMAN, 1981). Dessa forma, os termos framing positivo (mensagem/imagem positiva) e framing negativo (mensagem/imagem negativa) foram utilizados para explicar duas formas de expor, positiva ou negativamente, a mesma informação.

Uma forma de trabalhar a informação negativamente é o que tem sido feito pela ANVISA com as mensagens de advertências sanitárias contidas nos maços de cigarros que utilizam o apelo ao medo. Os apelos ao medo têm crescido em popularidade porque os anunciantes descobriram que eles aumentam o interesse e a persuasão (LATOUR; SNIPES; BLISS, 1996). Esse modo de apelo é utilizado em alguns tipos de campanhas cujo objetivo é o de estimular uma resposta emocional nas pessoas e essas decidirem por eliminar a ameaça

Além disso, a utilização de imagens impactantes com apelo ao medo, juntamente com mensagens de advertência, é mais eficiente que a utilização somente da imagem (GALLOPELMORVAN et al., 2011).

Uma meta-análise concluiu que o medo tem sido estudado em muitos contextos e que, quanto mais forte é o apelo do medo, maiores são a atitude, a intenção e as mudanças de comportamento (WITTE; ALLEN, 2000).

O nível de medo muito baixo será marcado por um apelo ineficaz e não capaz de comunicar a mensagem. Por outro lado, um nível de medo que é muito alto pode levar à negação do medo com pensamentos que sugerem outras razões para o efeito indesejado (SOAMES JOB, 1988). Campanhas que aumentam o nível de apelo ao medo podem obter resultados, visto que, nesse caso, atuam com uma persuasão significativamente maior. Entretanto, os altos níveis de medo podem gerar no indivíduo efeitos inibidores, bloqueando emocionalmente a mensagem e gerando rejeição à mesma.

Um estudo de Keller e Block (1996) também analisa o antitabagismo, porém relaciona 0 nível de medo com uma resposta de elaboração ao problema ou à solução. Segundo o autor, a eficácia de um apelo ao medo não é apenas relacionada com o nível de medo, mas a quão bem o problema (ou seja, câncer de pulmão) e a solução são elaborados na mensagem. Keller e Block (1996) sugerem que 
baixos níveis de medo podem não ser eficazes porque não há uma elaboração suficiente sobre as consequências prejudiciais, bem como que os apelos de medo de alto nível também podem ser ineficazes porque há muita elaboração.

Como existem divergências na literatura quanto ao uso do apelo ao medo, a utilização de mensagens positivas para esses anúncios pode também se tornar uma importante ferramenta. Por meio de mensagens e imagens positivas, campanhas de Marketing Social podem criar no seu públicoalvo maior afinidade com a ideia proposta, gerando maior confiança e quebrando barreiras criadas na mente que impediam a mudança (NEVES, 2001). A maioria dos fumantes, consoante Mota et al. (2012, p. 10), acreditam em melhor eficácia das campanhas antifumo se elas utilizassem mensagens positivas, destacando-se os benefícios de parar de fumar: "[...] daria mais resultado que campanhas que tentam amedrontar, porque o fumante não tem medo das advertências".

Outra questão relacionada ao uso de mensagens de apelo ao medo nas embalagens de cigarro é que estudos com 0 uso do neuromarketing demonstraram que as pessoas associam a imagem negativa ao efeito prazeroso do uso do cigarro (LINDSTROM, 2009). 0 autor retromencionado verificou que mensagens como 'Fumar mata' não levam ao resultado desejado, mas que esse tipo de mensagem gera um efeito contrário no cérebro humano. O que ocorre é que, ao olhar o maço de cigarros e o aviso nele contido, ativa-se o núcleo Accumbens do cérebro (zona de desejo), visto que, após acender o cigarro (mesmo olhando para o aviso), o fumante, dez segundos depois, irá se sentir bem, voltando o ciclo a se repetir em outros dez minutos posteriores. Com isso, o cérebro começa a associar a mensagem de advertência à sensação de prazer sentida ao fumar, tornando a mensagem ineficaz (LINDSTROM, 2009).

Além disso, Rothman et al. (2006) verificaram que, para campanhas publicitárias que alertam sobre problemas de saúde, o framing positivo se mostra mais eficiente quando a intenção é alertar sobre os fatores que podem impedir o aparecimento da doença, enquanto o framing negativo é mais efetivo para alertar como detectar a doença.

A adoção de advertências sanitárias positivas para influenciar o público-alvo pode surtir efeito, visto que estudos como o de Mota et al. (2012) demonstraram que fumantes defendem que esse tipo de mensagem teria maior impacto, uma vez que eles afirmam ignorar as mensagens de apelo ao medo por considerá-las muito apelativas e até mesmo fora da realidade.

Há uma estimativa que de $40 \%$ a $70 \%$ de todas as mortes prematuras e, aproximadamente, $66 \%$ das deficiências físicas poderiam ser evitadas por meio do controle de menos de dez dos fatores de risco, como dieta, exercícios, abuso de álcool, cigarro, entre outros (SIGNORELLI, 1993). Dessa forma, aumenta a importância de se compreender quais são os fatores 
que influenciam a eficácia dos apelos da mídia que visam a mudanças de comportamentos relacionados à saúde (MAYER; AVILA, 2010).

No que concerne ao cigarro, os apelos utilizados nas mensagens têm sido de medo, no entanto, como demonstrado anteriormente, há indícios de que apelos com mensagens positivas surtiriam melhor efeito em determinados consumidores.

Mota et al. (2012) defendem que tanto campanhas com apelo ao medo quanto campanhas com mensagens e imagens positivas deveriam ser utilizadas simultaneamente, atingindo a todos os fumantes de alguma maneira, o que poderia evitar o condicionamento do cérebro a apenas um tipo de advertência sanitária. As afirmações de Mota et al. (2012) estão alinhadas à TFR, visto que, de acordo com essa teoria, as pessoas mais preventivas são atingidas por mensagens distintas daquelas que atingem pessoas mais promocionais.

\subsection{Teoria do Foco Regulatório (TFR)}

A Teoria do Foco Regulatório, com foco no comportamento daquele que busca o prazer e evita a dor, descreve que o indivíduo tem seu comportamento fundamentado em suas motivações internas para alcançar seus objetivos traçados (HIGGINS, 1987, 1997). Essa abordagem, de acordo com Lima (2012), é composta por três princípios: Princípio da Antecipação Regulatória, Princípio da Referência Regulatória e Princípio do Foco Regulatório.

O Princípio da Antecipação Regulatória explicita que a motivação da pessoa é decorrente de suas expectativas e de como ela se antecipa frente aos resultados e consequências (positivas prazer, ou negativas - dor) de suas atitudes. Assim, Lima (2012) conceitua o comportamento de aproximação, apontando que as pessoas se aproximam, antecipadamente, de situações prazerosas, bem como conceitua o comportamento de afastamento, asseverando que as pessoas se afastam, também, de forma antecipada, de situações dolorosas.

Segundo o Princípio da Referência Regulatória, o indivíduo visa à autorregulação, utilizando-se de um ponto de referência, caracterizando-se os comportamentos de aproximação ou afastamento pelo "movimento" direcionado na busca de um resultado esperado ou no direcionamento contrário a um resultado indesejável (LIMA, 2012).

Quanto ao Princípio do Foco Regulatório, o indivíduo tem seu comportamento de aproximação ou afastamento determinado em estratégias de autorregulação. Quando o comportamento de autorregulação, visando a resultados positivos, tiver a referência regulatória contínua, podem ser utilizadas tanto estratégias de aproximação quanto estratégias de afastamento para que esses 
resultados sejam alcançados. Lima (2012) destaca dois tipos de estratégias: a estratégia com Foco de Promoção e a estratégia com Foco de Prevenção.

A estratégia com foco de prevenção explica um comportamento autorregulatório que busca segurança e proteção com vistas ao alcance dos objetivos relacionados à vigilância, garantias de rejeições assertivas e minimização de erros cometidos (HIGGINS, 1987; HIGGINS et al., 1994; CROWE; HIGGINS, 1997; FÖRSTER; HIGGINS; BIANCO, 2003; PHAM; HIGGINS, 2005). Por isso, acredita-se que:

$\mathbf{H}_{1}$ - Pessoas mais preventivas são mais afetadas por advertências sanitárias com apelo ao medo.

A estratégia com foco de promoção explica um comportamento autorregulatório que busca avanços e realização com vistas ao alcance dos objetivos com avidez, acertos e minimização de erros (HIGGINS, 1987; HIGGINS et al., 1994; CROWE; HIGGINS, 1997; FÖRSTER; HIGGINS; BIANCO, 2003; PHAM; HIGGINS, 2005). Por isso, acredita se que:

$\mathrm{H}_{2}$. Pessoas mais promocionais são mais afetadas por advertências sanitárias positivas.

Higgins $(1987,1997)$ observa que tanto o foco de promoção quanto o de prevenção são provenientes dos estados motivacionais originados das experiências sociais das pessoas.

\section{PROCEDIMENTOS METODOLÓGICOS}

Para o alcance do objetivo proposto, delineou-se uma pesquisa com utilização do método experimental, pois tal método é o mais adequado para avaliar uma relação causal (MALHOTRA, 2006). Por meio desse processo, é possível compreender a relação de causa e efeito existente nos fenômenos mercadológicos (HERNANDEZ; BASSO; BRANDÃO, 2014). Importante destacar que a pesquisa experimental em marketing vem crescendo, principalmente, na busca de uma melhor compreensão do comportamento do consumidor (SILVA; LOPES, 2016).

Pelo método experimental, é possível manipular ou controlar uma ou mais variáveis independentes, observando e mensurando os efeitos e variações que essa manipulação exerce sobre uma ou mais variáveis dependentes (SHADISH; COOK; CAMPBELL, 2002; MALHOTRA, 2006). Dessa forma, será possível inferir relações causais, uma vez que, com esse método, o pesquisador irá controlar uma "causa" potencial e observar a mudança correspondente nos efeitos supostos (HAIR JR 
et al., 2005; MALHOTRA, 2006). Portanto, o objetivo principal da realização de um experimento é obter conclusões válidas dos efeitos de variáveis independentes sobre o grupo em estudo (MALHOTRA, 2006).

Para verificar a influência das advertências sanitárias com apelo ao medo e das advertências sanitárias positivas na intenção de parar de fumar e na emoção (culpa e vergonha) dos fumantes, o experimento desenvolvido adotou o desenho fatorial com formato $2 \times 2$, sendo duas advertências sanitárias (advertência sanitária de apelo ao medo versus advertência sanitária positiva) e dois focos regulatórios (promocional versus preventivo).

Como instrumento para coleta de dados, utilizou-se um questionário composto por seis seções, constando, primeiramente, a escala do foco regulatório (promoção vs. prevenção) para que o respondente não sofresse influência do estímulo. Em seguida, constam os estímulos utilizados, as demais escalas e as questões demográficas para conhecimento do perfil dos respondentes.

A amostra da pesquisa foi formada por consumidores fumantes de uma cidade do interior de Minas Gerais. Para que se chegasse a esse tipo de amostra intencional, foi empregada, para a coleta dos dados, a técnica snowball sampling ou amostragem em bola de neve. Essa técnica é bastante utilizada nas pesquisas sociais em que os participantes iniciais do estudo indicam novos participantes que, por sua vez, indicam novos participantes e, assim, sucessivamente, até que seja alcançado o objetivo proposto (o "ponto de saturação"). O "ponto de saturação" é atingido quando os novos respondentes passam a repetir os conteúdos já obtidos em entrevistas anteriores sem acrescentar novas informações relevantes à pesquisa (BALDIN; MUNHOZ, 1994).

Segundo Sanchez e Nappo (2002), a escolha de sujeitos por meio da snowball sampling, a partir dos informantes-chave, permite que os pesquisadores se aproximem da população investigada, além de fornecer subsídios para a elaboração dos instrumentos de pesquisa que possam, futuramente, ser incorporados à investigação.

Para aplicação do questionário, foram preparadas três versões, sendo a única diferença entre elas os estímulos apresentados na primeira seção do instrumento de pesquisa. Em uma versão, o estímulo compreendia a advertência sanitária positiva; em outra, a advertência sanitária com apelo ao medo, e, em uma terceira, não constava qualquer advertência (controle). A aplicação do instrumento foi feita de forma randomizada para que todos os fumantes tivessem oportunidade de responder a qualquer questão apresentada, tendo sido cada versão aplicada a trinta indivíduos, totalizando uma amostra de noventa fumantes, sendo 30 fumantes em cada um dos três grupos (expostos a mensagens positivas, negativas e controle), atendendo, dessa forma, aos preceitos de Pallant (2001), 0 qual considera plausivel que cada grupo no estudo experimental contenha pelo menos 30 indivíduos. Os dados coletados no ano de 2015 foram analisados por meio da análise de frequência, para os 
dados categóricos, bem como por meio de análise fatorial exploratória (AFE) das escalas e análise de variância (ANOVA), tendo sido utilizado o software SPSS versão 21.0.

\subsection{Variáveis que compõem o experimento}

As variáveis dependentes e independentes estão apresentadas no Quadro 1.

Quadro 1 - Classificação das variáveis da pesquisa

\begin{tabular}{|l|l|}
\hline \multicolumn{1}{|c|}{ Função da variável no fenômeno } & \multicolumn{1}{c|}{ Definição das Variáveis no Experimento } \\
\hline Variáveis dependentes (efeito) & $\begin{array}{l}\text { 1) Intenção de parar de fumar. } \\
\text { 2) Emoção (culpa e vergonha). }\end{array}$ \\
\hline $\begin{array}{l}\text { Variáveis independentes (causa) - (variáveis } \\
\text { manipuladas ou mensuradas) }\end{array}$ & $\begin{array}{l}\text { 1) Foco Regulatório (promoção e prevenção). } \\
\text { 2) Propaganda (advertência sanitária positiva vs negativa). }\end{array}$ \\
\hline
\end{tabular}

Fonte: Dados da pesquisa (2015).

\subsection{Definição dos estímulos}

Para definição dos estímulos, foram escolhidas, aleatoriamente, dez advertências sanitárias de apelo ao medo. Essas advertências eram utilizadas nas embalagens de cigarros no Brasil na época da coleta de dados, sob orientação do Ministério da Saúde em campanhas contra o tabagismo. Outras dez imagens foram usadas, representando imagens positivas de pessoas saudáveis, as quais também foram escolhidas aleatoriamente, tendo sido as imagens apresentadas para um grupo de vinte pessoas. Desse total, dez pessoas avaliaram somente a imagem positiva e outras dez avaliaram somente a advertência sanitária com apelo ao medo, e elencaram a imagem de maior apelo ao medo e a imagem mais positiva para serem utilizadas em campanhas contra o uso do cigarro.

Entretanto, quanto à escolha da imagem com apelo ao medo, obtiveram-se, como resultado, imagens com margem de votos muito próxima, recebendo a imagem mais votada três votos. Em segundo lugar, duas imagens obtiveram dois votos cada e, por último, três imagens receberam um voto cada. Diante desse resultado, procedeu-se a uma nova pesquisa, apresentando-se as três imagens de apelo ao medo mais votadas a um novo grupo composto por outras dez pessoas, cujo objetivo era a escolha da imagem mais apelativa. 0 resultado dessa nova pesquisa apontou para a mesma imagem mais votada anteriormente, à qual foram atribuídos seis votos. Já a segunda imagem mais votada obteve três votos e a última, apenas um voto. 
Todavia, como a Teoria do Foco Regulatório, base conceitual desta pesquisa, analisa 0 foco regulatório com base em promoção/prevenção do ponto de vista do self e a imagem mais votada foi a que representa um terceiro (bebê) e não a si mesmo, optou-se pelo uso da segunda imagem mais votada para o uso como estímulo. Nas Figuras 3 e 4, apresentadas lado a lado, visualizam-se as imagens de advertências sanitárias utilizadas.

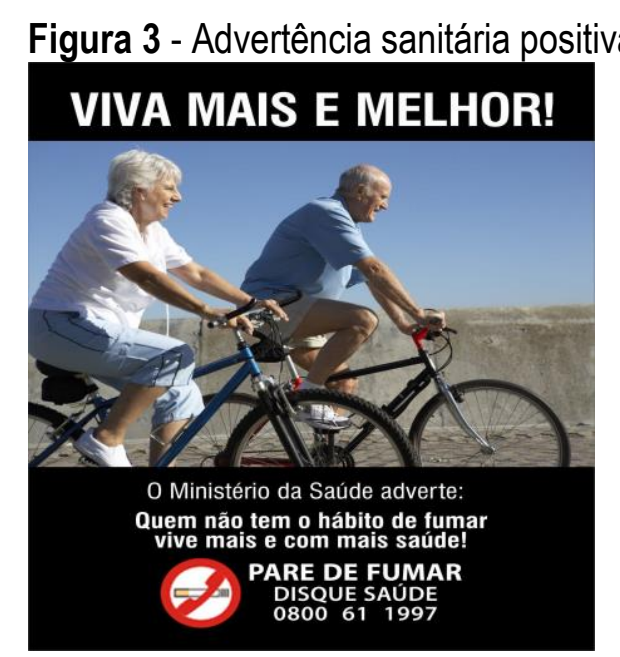

Fonte: Adaptado de OSAF (2012).

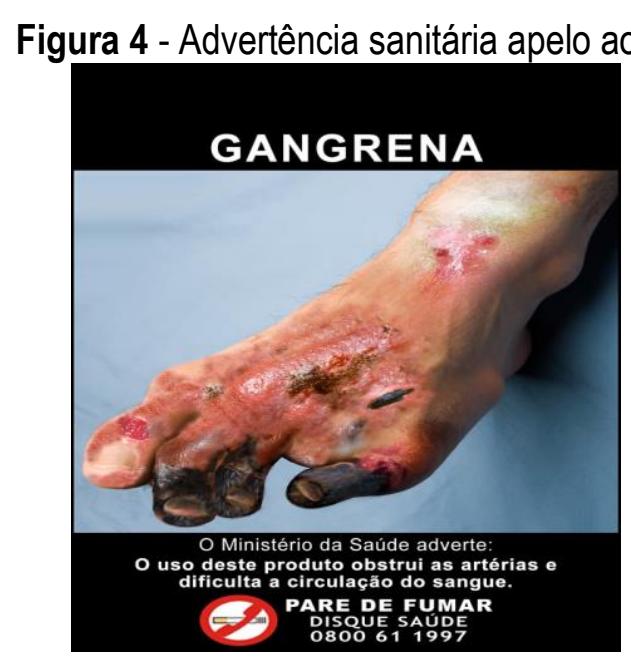

Fonte: ANVISA (2014).

Importante destacar que procedimento idêntico foi utilizado para a imagem positiva e que a imagem mais votada recebeu 05 (cinco) votos já na primeira apresentação ao grupo de dez pessoas. Assim, na aplicação do questionário, foram utilizadas como estímulos duas advertências sanitárias: uma de apelo ao medo e outra positiva. Para o grupo controle, não havia nenhuma imagem, pois esse grupo foi usado para controlar os efeitos dos estímulos nos dois outros grupos experimentais (com mensagem positiva e negativa). Por fim, noventa fumantes responderam 0 instrumento de pesquisa, sendo trinta para cada situação (mensagem/imagem positiva, apelo ao medo e controle). Após a definição dos estímulos, foram definidas as escalas utilizadas no instrumento de pesquisa.

\subsection{Escalas utilizadas}

A escala usada na primeira seção do questionário foi a escala de foco regulatório. $A$ escala de cinco pontos varia de 'discordo totalmente' até 'concordo totalmente', sendo cinco assertivas relativas à promoção e outras cinco, à prevenção, conforme estabelecido por Lockwood, Jordon e Kunda (2002). Na terceira seção do questionário, utilizou-se a escala de intenção de comportamento geral proposta por Fishbein e Ajzen (1975) com adaptações de Taylor e James (2005) citados por (BRUNER, 2009). A escala adotada é uma escala de diferencial semântico de cinco pontos. 
$\mathrm{Na}$ quarta seção, utilizou-se a escala de emoção (culpa e vergonha) proposta por Laskoski, Natividade e Hutz (2013), enquanto a quinta seção compreendeu o manipulation check (checagem dos estímulos), tendo sido elaboradas quatro questões para confirmar se as imagens positivas realmente eram consideradas positivas pelos respondentes, bem como se as imagens de apelo ao medo eram realmente assim consideradas. Por fim, a sexta seção compreendeu a caracterização do entrevistado com base no estudo de variáveis demográficas.

\section{$4 \quad$ ANÁLISE E DISCUSSÃO DOS RESULTADOS}

A discussão dos resultados empíricos é apresentada em quatro subseções com destaque para o perfil descritivo do entrevistado. Na sequência, são discutidas a análise fatorial exploratória das escalas, a checagem dos estímulos utilizados e a análise de variância (ANOVA). Como procedimento geral, adotou-se o valor do nível de significância em todos os testes de hipótese de $5 \%(\square=0,05)$.

\subsection{Perfil do entrevistado}

Dentre os noventa indivíduos que compuseram a amostra intencional, sendo todos fumantes, $77,8 \%$ são do gênero masculino e $22,2 \%$ são do gênero feminino. Em relação à idade dos respondentes, 35,6\% tinham idade variável entre 18 a 23 anos, 17,8\% estavam na faixa etária entre 24 a 29 anos, $22,2 \%$ declararam ter idade acima dos 48 anos e os demais estavam em outras faixas etárias. Quanto ao estado civil, $57,8 \%$ eram solteiros, 7,8\% encontravam-se divorciados, $23,3 \%$ eram casados e $11,1 \%$ declararam ter outro tipo de estado civil. Também foram caracterizados os respondentes quanto à sua condição de residência, sendo as seguintes: 30,0\% moram com seu cônjuge, 22,2\% residem em república e 15,6\% moram com os pais, apontando os demais terem outra forma de residência.

Em relação à escolaridade dos respondentes, 41,1\% possuem ensino fundamental incompleto, $24,4 \%$ possuem ensino superior incompleto e os demais declararam outros níveis de escolaridade. Por fim, em relação à renda familiar mensal, 16,7\% declararam ter renda de até $\mathrm{R} \$ 776,00,7,8 \%$ afirmaram ter renda de $\mathrm{R} \$ 777,00$ até $\mathrm{R} \$ 1147,00,33,3 \%$ apontaram ter renda de $R \$ 1148,00$ até $R \$ 1685,00,16,7 \%$ declaram ter renda de $R \$ 1686,00$ até $R \$ 2654,00,16,7 \%$ declaram ter renda de $\mathrm{R} \$ 2655,00$ até $\mathrm{R} \$ 5241,00$ e os demais apontaram outras faixas de renda. 


\subsection{Análise Fatorial Exploratória}

As variáveis foram testadas com o fim de verificar a sua dimensionalidade. Em seguida, realizou-se a análise fatorial exploratória da escala de Foco Regulatório, a qual, após a eliminação das assertivas PROMO3; PREV1 e PREV4, por terem demonstrado baixas comunalidades $(<0,50)$, foi definida em dois fatores e se mostrou adequada. O primeiro fator, com variância explicada de 33,73\%, agrupou os indicadores de mensuração do perfil promocional (PROMO) e o segundo fator, com explicação de 27,25\%, agrupou os indicadores para estimação do perfil preventivo (PREVE). 0 coeficiente alfa de Cronbach também se mostrou adequado para os dois fatores $(>0,70)$, conforme exposto na Tabela 1.

Tabela 1 - Análise fatorial exploratória da escala Foco Regulatório

\begin{tabular}{|c|c|c|c|c|c|}
\hline Itens da escala incluídos no fator & $\begin{array}{l}\text { Carga } \\
\text { PROMO }\end{array}$ & $\begin{array}{l}\text { Carga } \\
\text { PREVE }\end{array}$ & $\begin{array}{l}\text { Variância } \\
\text { explicada }\end{array}$ & $\begin{array}{l}\text { Alfa de } \\
\text { Cronbach }\end{array}$ & KMO \\
\hline $\begin{array}{l}\text { Eu, frequentemente, imagino como atingir minhas aspirações e } \\
\text { esperanças (PROMO1). }\end{array}$ & 0,787 & $-0,159$ & \multirow{4}{*}{$33,73 \%$} & \multirow{4}{*}{0,755} & \multirow{7}{*}{0,639} \\
\hline $\begin{array}{l}\text { Eu, normalmente, foco em alcançar resultados positivos em minha } \\
\text { vida (PROMO2). }\end{array}$ & 0,762 & $-0,170$ & & & \\
\hline $\begin{array}{l}\text { Eu, frequentemente, me imagino experimentando coisas boas que } \\
\text { desejo aconteça (PROMO4). }\end{array}$ & 0,737 & $-0,025$ & & & \\
\hline $\begin{array}{l}\text { Eu, tipicamente, foco no sucesso que espero alcançar no futuro } \\
\text { (PROMO5). }\end{array}$ & 0,764 & $-0,080$ & & & \\
\hline $\begin{array}{l}\text { Por vezes, eu imagino que coisas más possam acontecer comigo } \\
\text { no dia a dia (PREV2). }\end{array}$ & 0,210 & 0,831 & \multirow{3}{*}{$27,25 \%$} & \multirow{3}{*}{0,873} & \\
\hline $\begin{array}{l}\text { Eu sou mais focado na prevenção de perdas do que em obter } \\
\text { ganhos (PREV3). }\end{array}$ & 0,194 & 0,759 & & & \\
\hline Eu tenho receio e medo do que posso ser no futuro (PREV5). & 0,019 & 0,799 & & & \\
\hline
\end{tabular}

Fonte: Dados da pesquisa (2015).

O procedimento também foi realizado para a variável dependente intenção de parar de fumar (IPF) por meio da agregação das nove afirmativas ( $\alpha=0,946)$. O KMO foi 0,892 e a porcentagem da variância explicada pelo fator foi de 70,30\%, conforme pode ser visto na Tabela 2.

Tabela 2 - Análise fatorial exploratória da escala de comportamento geral (intenção de parar de fumar)

\begin{tabular}{|c|c|c|c|c|}
\hline Itens da escala incluídos no fator & $\begin{array}{l}\text { Carga } \\
\text { IPF }\end{array}$ & $\begin{array}{l}\text { Variância } \\
\text { explicada }\end{array}$ & $\begin{array}{l}\text { Alfa de } \\
\text { Cronbach }\end{array}$ & $\mathrm{KMO}$ \\
\hline \multicolumn{5}{|l|}{ 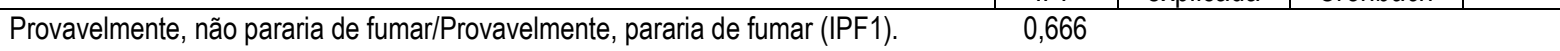 } \\
\hline \multicolumn{5}{|l|}{$\begin{array}{l}\text { Não existe a possibilidade de eu parar de fumar/ Existe a possibilidade de eu parar } \\
\text { de fumar (IPF2). }\end{array}$} \\
\hline É improvável que eu pare de fumar/ É provável que eu pare de fumar (IPF3). & 0,880 & & & \\
\hline É impossível que eu pare de fumar/ É possivel que eu pare de fumar (IPF4). & 0,842 & & & \\
\hline Não tenho certeza se pararia de fumar/ Certamente, pararia de fumar (IPF5). & 0,822 & & & \\
\hline Definitivamente, não pararia de fumar/ Definitivamente, pararia de fumar (IPF6). & 0,914 & $70,30 \%$ & 0,946 & 0,892 \\
\hline De forma alguma, pararia de fumar/ É uma forma de eu parar de fumar (IPF7). & 0,885 & & & \\
\hline Não há chance de eu parar de fumar/ Há chance de eu parar de fumar (IPF8). & 0,831 & & & \\
\hline Provavelmente, não pararia de fumar/ Provavelmente, pararia de fumar (IPF9). & 0,865 & & & \\
\hline
\end{tabular}

Fonte: Dados da pesquisa (2015). 
Destaca-se que a variável dependente 'emoção-culpa' também foi submetida à análise fatorial, cujos resultados são apresentados na Tabela 3. Em relação a essa variável, agregaram-se ao fator nove das onze assertivas que compunham o modelo, excetuando-se as assertivas CULPA8 e CULPA9 ( $\alpha=0,908)$. O KMO foi 0,881 , sendo $57,88 \%$ a variância explicada pelo fator.

Tabela 3 - Análise fatorial exploratória da escala de emoção - culpa

\begin{tabular}{|c|c|c|c|c|}
\hline Itens da escala incluídos no fator & $\begin{array}{l}\text { Carga } \\
\text { CULPA }\end{array}$ & $\begin{array}{l}\text { Variância } \\
\text { explicada }\end{array}$ & $\begin{array}{l}\text { Alfa de } \\
\text { Cronbach }\end{array}$ & KMO \\
\hline Sinto-me mal quando quero fazer algo que sei que não é correto (CULPA1). & 0,812 & & & \\
\hline Sinto-me mal depois de ter feito algo errado (CULPA2). & 0,801 & & & \\
\hline Às vezes, sinto-me culpado (a) quando quero fazer algo ruim (CULPA3). & 0,751 & & & \\
\hline Sinto-me mal quando sei que deveria ter feito algo, mas não o fiz (CULPA4). & 0,789 & & & \\
\hline $\begin{array}{l}\text { Quando eu me sinto culpado (a) por ter prejudicado alguém, tento reparar os danos } \\
\text { causados (CULPA5). }\end{array}$ & 0,744 & 57,88 & 0,908 & 0,881 \\
\hline $\begin{array}{l}\text { Sinto-me culpado(a) por algo que eu não fiz, mas sei que deveria ter feito } \\
\text { (CULPA6). }\end{array}$ & 0,647 & & & \\
\hline $\begin{array}{l}\text { Sinto remorso por ter feito algo que eu não deveria ter feito (CULPA7). } \\
\text { Gostaria de não ter feito alqumas coisas que eu fiz (CULPA10). }\end{array}$ & $\begin{array}{l}0,794 \\
0,684\end{array}$ & & & \\
\hline $\begin{array}{l}\text { Sinto-me mal por ter feito alguma coisa, apesar de saber que não era a coisa certa a } \\
\text { se fazer (CULPA11). }\end{array}$ & 0,807 & & & \\
\hline
\end{tabular}

Em relação à variável dependente 'emoção-vergonha', foram agregadas ao fator sete das oito assertivas que compunham o modelo, visto que a assertiva VERG6 não aderiu ao fator, sendo $a=$ 0,888. O KMO foi 0,848 e a porcentagem da variância explicada foi de $60,30 \%$, como sintetizado na Tabela 4.

Tabela 4 - Análise fatorial exploratória da escala de emoção-vergonha

\begin{tabular}{|c|c|c|c|c|}
\hline Itens da escala incluídos no fator & $\begin{array}{l}\text { Carga } \\
\text { VERG }\end{array}$ & $\begin{array}{l}\text { Variância } \\
\text { explicada }\end{array}$ & $\begin{array}{l}\text { Alfa de } \\
\text { Cronbach }\end{array}$ & KMO \\
\hline $\begin{array}{l}\text { Às vezes, sinto-me impedido de fazer alguma coisa por medo de ser julgado (a) } \\
\text { (VERG1). }\end{array}$ & 0,714 & \multirow{7}{*}{60,30} & \multirow{7}{*}{0,888} & \multirow{7}{*}{0,848} \\
\hline Sinto medo de ser julgado (a) por minhas ações (VERG2). & 0,878 & & & \\
\hline Sinto medo de ser julgado (a) por ser quem eu sou (VERG3). & 0,811 & & & \\
\hline $\begin{array}{l}\text { Às vezes, não faço algo que eu desejo fazer por medo do que as outras } \\
\text { pessoas vão dizer ou pensar (VERG4). }\end{array}$ & 0,843 & & & \\
\hline Tenho medo do que as pessoas podem dizer ou pensar sobre mim (VERG5). & 0,799 & & & \\
\hline $\begin{array}{l}\text { Sinto-me mal por algumas ações que eu cometi e que outras pessoas viram ou } \\
\text { ouviram dizer sobre (VERG7). }\end{array}$ & 0,750 & & & \\
\hline Sinto-me inferior às outras pessoas (VERG8). & 0,610 & & & \\
\hline
\end{tabular}

Fonte: Dados da pesquisa (2015).

\subsection{Checagem dos estímulos}

Para checar o sucesso dos estímulos apresentados, os respondentes analisaram quatro frases sobre as imagens/mensagens apresentadas. Se a resposta marcada fosse 1 (um) significava que o estímulo transmitiu a mensagem desejada, ou seja, o cigarro é prejudicial à saúde e a vida sem cigarro é mais saudável. Se a resposta obtida fosse 2 (dois) significava que o estímulo não transmitiu ao respondente 0 quanto o cigarro causa danos à saúde e que a vida sem cigarro é mais saudável. $\mathrm{A}$ média para a primeira frase foi de 1,42 e, para a segunda e a terceira, foi de 1,36. Para a quarta fase, a 
média foi de 1,34, ou seja, todas as médias foram próximas de 1 (sim), significando que o estímulo, efetivamente, transmitiu a mensagem. Sendo assim, as assertivas para checagem dos estímulos obtiveram respostas conforme o esperado, sustentando a manipulação estrutural da mensagem.

\subsection{Análise de variância (ANOVA)}

A análise de variância evidenciou que nem a culpa e nem a vergonha são significantes para o modelo, pois não há efeito principal, tendo sido verificado o efeito de interação entre as variáveis culpa e vergonha $(F(2,512)=84,44$ e p<0,05). Na análise da variável culpa em relação à intenção de parar de fumar, encontrou-se $(F(1,017)=30,06$ e $p>0,05)$ e, para a variável vergonha, encontrou-se $(F(1,540)=41,38$ e $p>0,05)$.

Também não foi verificado efeito de interação entre as variáveis mensagens positiva e negativa $(F(1,162)=53,07$ e p>0,05). Já em relação à intenção de parar de fumar, não foi encontrado efeito principal para o estímulo (propaganda com advertência sanitária negativa e positiva) $(F(0,196)=$ 0,68 e $p>0,05$ ). Percebe-se, portanto que as advertências sanitárias (positiva ou negativa) não influenciam a intenção de parar de fumar dos fumantes.

Os resultados observados contrariam tanto as constatações de Mota et al. (2012), segundo as quais os fumantes declararam que campanhas antitabagismo que apresentassem advertências sanitárias positivas seriam mais eficazes para influenciar o fumante a parar de fumar, quanto as de Neves (2001), o qual enfatiza que, por meio da mensagem/imagem positiva, o marketing social pode criar no seu público-alvo maior afinidade com a ideia proposta, gerando maior confiança e quebrando barreiras criadas na mente que impediam a mudança. Além disso, esses resultados contrariam também o exposto por Rothman et al. (2006), os quais verificaram que, para campanhas publicitárias que alertam sobre problemas de saúde, o framing positivo se mostra mais eficiente quando a intenção é alertar sobre os fatores que podem impedir o aparecimento de doenças.

Quanto ao foco regulatório, confirmou-se que há efeito principal para a intenção de parar de fumar $(F(17,665)=25,40$ e p<0,05). Ainda, identificou-se que não há efeito de interação entre o foco regulatório e 0 estímulo (propaganda com advertências sanitárias positivas e negativas) $(F(3,669)=$ $2,40$ e $p>0,05)$. Percebe-se, portanto, que os fumantes com perfil promocional tendem a ter uma maior intenção de parar de fumar do que os fumantes preventivos.

Essa constatação vem ao encontro da teoria da estratégia com foco de promoção de Higgins (1987, 1997), segundo a qual as pessoas com perfil promocional são aquelas que focam na realização de suas metas, buscam alcançar seus objetivos com maior intensidade e procuram diminuir seus erros. Isso justifica o fato de a intenção de parar de fumar ter sido maior no caso de pessoas com 
perfil promocional. Entretanto, o fato de essas pessoas terem maior intenção de parar de fumar não muda o fato de que as advertências sanitárias utilizadas nas embalagens de cigarro ou as advertências propostas e utilizadas como estímulo neste estudo ainda não são suficientes para diminuir o uso de cigarros.

Apesar de pessoas com perfil preventivo buscarem mais segurança, proteção e minimização dos erros, elas não são como as de perfil promocional, as quais buscam alcançar seus resultados com maior intensidade, por isso tanto a advertência sanitária com apelo ao medo quanto a positiva não contribuíram para influenciar na intenção de parar de fumar. Rejeita-se, portanto, as hipóteses apresentadas neste estudo, as quais propuseram que pessoas mais preventivas são mais afetadas por advertências sanitárias com apelo ao medo e que pessoas mais promocionais são mais afetadas por advertências sanitárias positivas.

\section{CONCLUSÕES}

O presente estudo teve como objetivo verificar a influência das advertências sanitárias com apelo ao medo presentes nas embalagens dos cigarros, bem como a influência das advertências sanitárias positivas na intenção de parar de fumar e na emoção (culpa e vergonha) dos fumantes. A expectativa era que, a partir dos estímulos apresentados (framing positivo e negativo) os consumidores de cigarro fossem influenciados quanto à intenção de parar de fumar e em relação às suas emoções perante 0 cigarro.

Por meio da análise dos dados obtidos e da análise da variância (ANOVA), pode-se observar que tanto a imagem/mensagem com apelo ao medo (framing negativo) quanto a de imagem/mensagem positiva (framing positivo) não apresentaram influência para que os fumantes tivessem a intenção de parar de fumar. Tal situação pode ser justificada pelo fato de o uso da nicotina gerar vício e, por isso, o fumante pode necessitar de tratamento médico para conseguir parar de fumar e não apenas de uma comunicação persuasiva. Dessa forma, os pesquisadores vislumbram que, a partir do resultado desta pesquisa, seja necessário verificar os efeitos desses estímulos com não fumantes, pois acredita-se que tais estímulos funcionem como prevenção já que, de forma isolada, não foram suficientemente eficazes para gerar a intenção de parar de fumar dos dependentes de tabagismo.

Apesar dos framings positivos e negativos não terem surtido o efeito esperado, foi possível constatar efeito quanto ao foco regulatório, confirmando-se que os fumantes com perfil promocional tendem a ter uma maior intenção de parar de fumar do que os fumantes preventivos. 
Dessa forma, a pesquisa contribui com informações relevantes de conscientização para balizar possíveis políticas públicas para o combate ao uso do cigarro, mostrando que os consumidores têm intenções distintas dependendo do seu perfil (promocional ou preventivo) e que, por isso, as estratégias de combate ao uso do tabaco devem levar em consideração essas diferenças, pois os fumantes são persuadidos de formas distintas.

Para a realização deste estudo, foram encontradas algumas limitações, especialmente, quanto à composição da amostra, visto ter se deparado com fumantes que, por algum motivo, sentiam vergonha de dizer que fumavam. Destaca-se ainda que, como a pesquisa foi realizada apenas com fumantes, é possível sugerir, para estudos futuros, uma pesquisa que utilize amostras com pessoas fumantes e não fumantes, pois o efeito da advertência sanitária para não fumantes (na intenção de influenciá-los a não fumarem) pode ser diferente do efeito para fumantes (na intenção de fazê-los parar de fumar).

Também, podem ser realizadas investigações com amostras constituídas por fumantes com diferentes graus de escolaridade, como universitários e não universitários, ou, ainda, com pessoas de faixas etárias distintas com a finalidade de confirmar se a percepção quanto às advertências sanitárias se mantém. Outra variável que poderia ser investigada refere-se ao gênero, pois acredita-se que mulheres sejam mais suscetíveis à emoção, podendo os resultados, nesse caso, evidenciarem considerações interessantes. Nesta pesquisa, os dados categóricos não foram equalizados e, por isso, seria frágil fazer essas inferências.

Outra sugestão é que se aprofundem os estudos no campo do neuromarketing no que concerne ao uso do tabaco, tendo em vista que esse é um campo que procura entender melhor as reações que acontecem no cérebro dos fumantes e suas percepções frente às campanhas contra 0 tabagismo, analisando o quanto elas realmente têm sido eficazes.

\section{REFERÊNCIAS}

ALIYEV, F.; WAGNER, R. Cultural influence on luxury value perceptions: Collectivist vs. individualist luxury perceptions. Journal of International Consumer Marketing, v. 30, n. 33, p. 158-172, 2018. AMB. Comissão de combate ao tabagismo. Disponível em: https://amb.org.br/comissao-de-combateao-tabagismo/. Acesso em: 23 jun. 2014.

ANDREASEN, A. R. Social marketing: its definition and domain. Journal of Public Policy \& Marketing, v. 13, n. 1, p. 108-114, 1994.

ANDREASEN, A. R. Marketing social marketing in the social change marketplace. Journal of Public Policy \& Marketing, v. 21, n. 1, p. 3-13, 2002. 
ANTONETTI, P.; MAKLAN, S. Feelings that Make a Difference: How Guilt and Pride Convince Consumers of the Effectiveness of Sustainable Consumption Choices. Journal of Business Ethics, v. 124, n. 1, p. 117-134, 2014. https://doi.org/10.1007/s10551-013-1841-9

ANVISA. Publicadas novas imagens para embalagens de derivados do tabaco. Disponível em: http://portal.anvisa.gov.br/documents/106510/106594/A+Anvisa+e+o+Controle+dos+Produtos+Derivad os+do+Tabaco/4af73983-9d76-4af4-93c0-e35f153a18a7. Acesso em: 25 ago. 2014.

ANVISA. Publicadas novas imagens para embalagens de derivados do tabaco. Disponível em: http://portal.anvisa.gov.br/documents/106510/106594/Manual+de+Aplica\%C3\%A7\%C3\%A30+das+Adv ert\%C3\%AAncias+Sanit\%C3\%A1 rias/5bc7317c-bd47-4cd9-9572-44c8408f3a82. Acesso em: 21 nov. 2018.

BAGOZZI, R. P.; MOORE, D. J. Public Service Advertisements: Emotions and Empathy Guide Prosocial Behavior. Journal of Marketing, p. 58, n. 1, p. 56-70, 1994. https://doi.org/10.2307/1252251

BALDIN, N.; MUNHOZ, E. M. B. Snowball (bola de neve): uma técnica metodológica para pesquisa em educação ambiental comunitária. In: Congresso Nacional de Educação-EDUCRE/I Seminário Internacional de Representações Sociais, Subjetividade e Educação-SIRSSE, 10, 2011. Anais... Curitiba, PR, 7. p. 329-41, 2011.

BRASIL. Lei n 9.294, de 15 de julho de 1996. Dispõe sobre as restrições ao uso e à propaganda de produtos fumígeros, bebidas alcoólicas, medicamentos, terapias e defensivos agrícolas, nos termos do $\S 4^{\circ}$ do art. 220 da Constituição Federal. Diário Oficial [da República Federativa do Brasil], Brasília, DF, Seção 1 - 16/7/1996, Página 13074. Disponível em: http://www.planalto.gov.br/ccivil_03/Leis/L9294.htm. Acesso em: 16 jun. 2014.

BRASIL. Número de fumantes no país diminuiu nos últimos 25 anos. 17/04/2017. Disponível em http://www.brasil.gov.br/noticias/saude/2017/04/Numero-de-fumantes-no-pais-diminuiu-nos-ultimos-25anos. Acesso em: 21 nov. 2018.

BRUNER, G. C.. Marketing Scales Handbook: A Compilation of Multi-Item Measures for Consumer Behavior \& Advertising Research. 5. ed. Carbondale: Copyright @ 2009.

CAVALCANTE, T. M. O controle do tabagismo no Brasil: avanços e desafios. Revista Psiquiatria Clínica. v. 32, n. 5, p. 283-300, 2005.

COTTE, J.; COULTER, R. A.; MOORE, M. Enhancing or disrupting guilt: the role of ad credibility and perceived manipulative intent. Journal of Business Research, v. 58, n. 3, p. 361-368, 2005. https://doi.org/10.1016/S0148-2963(03)00102-4

CROWE, E.; HIGGINS, E. T. Regulatory focus and strategic inclinations: promotion and prevention in decision-making. Organizational Behavior and Human Decision Processes, v. 69, n. 2, p. 117-132, 1997.

FÖRSTER, J.; HIGGINS, E. T.; BIANCO, A. T. Speed/Accuracy decisions in task performance: built-in trade-off or separate strategic concerns? Organizational Behavior and Human Decision Processes, v. 90 , n. 1, p. 148-164, 2003.

GALLOPEL-MORVAN, K. et al. The use of visual warnings in social marketing: the case of tobacco. Journal of Business Research, v. 64, n. 1, p. 7-11, 2011. 
G1. Governo lança novas imagens para embalagens de cigarro: iniciativa faz parte das comemorações do Dia Mundial sem Tabaco. 27/05/2008. Brasil/Tabagismo. Disponível em: http://g1.globo.com/Noticias/Brasil/0,,MUL579986-5598,00-

GOVERNO+LANCA+NOVAS+IMAGENS+PARA+EMBALAGENS+DE+CIGARRO.html. Acesso em: 23 jun. 2014.

HAIR JR et al. Fundamentos de Métodos de Pesquisa em Administração. Porto Alegre: Bookman, 2005.

HERNANDEZ, J. M.; BASSO, K.; BRANDÃO, M. M. Pesquisa experimental em marketing. REMark, v. 13, n. 2, p. 98-117, 2014.

HIGGINS, E. T. Self-discrepancy: a theory relating self and affect. Psychological Review, v. 94, n. 3, p. 319-340, 1987.

HIGGINS, E. T. The self digest: self-knowledge serving self-regulatory functions. Journal of Personality and Social Psychology, v.71, n. 6, p. 1062-1083, 1996.

HIGGINS, E. T. Beyond pleasure and pain. American psychologist, v. 52, n. 12, p. 1280-1300, 1997.

HIGGINS, E. T.; RONEY, C. J., CROWE, E.; HYMES, C. Ideal versus ought predilections for approach and avoidance distinct self-regulatory systems. Journal of personality and social psychology, v. 66, n. 2, p. 276-286, 1994.

HORTENSE, F. T. P.; CARMAGNANI, M. I. S.; BRÊTAS, A. C. P. O significado do tabagismo no contexto do câncer de laringe. Revista Brasileira de Enfermagem, v. 61, n.1, p. 24-30, 2008.

INSTITUTO BRASILEIRO DE GEOGRAFIA E ESTATÍSTICA. IBGE e Ministério da Saúde recebem prêmio internacional por pesquisa sobre tabagismo. 2008. Disponível em:

http://saladeimprensa.ibge.gov.br/noticias?view=noticia\&id=1\&idnoticia=1579\&busca=1\&t=ibge-

ministerio-saude-recebem-premio-internacional-pesquisa-sobre-tabagismo. Acesso em: 17 jun. 2014.

INSTITUTO NACIONAL DE CÂNCER - INCA. Doenças associadas ao uso dos derivados do tabaco. 2014a. Disponível em:

http://www.inca.gov.br/tabagismo/frameset.asp?item=atento\&link=doencas.htm. Acesso em: 22 jun. 2014.

INSTITUTO NACIONAL DE CÂNCER - INCA. Número de fumantes no Brasil cai $\mathbf{2 0 , 5} \%$ em cinco anos. 2014b. Disponível em:

http://www2.inca.gov.br/wps/wcm/connect/agencianoticias/site/home/noticias/2014/numero_de_fumante s_no_brasil_cai_20_por_cento_em_cinco_anos. Acesso em: 5 jun. 2015.

KAHNEMAN, D.; TVERSKY, A. Prospect theory: an analysis of decision under risk. Econometrica, v. 47, n. 2, p. 263-291, 1979.

KELLER, P. A.; BLOCK, L. G. Increasing the persuasiveness of fear appeals: The effect of arousal and elaboration. Journal of Consumer Research, v. 22, n. 4, p. 448-459, 1996. 
KIM, Y. Cultural Orientation Affects Consumer Responses to Charity Advertising. Social Behavior and Personality: An International Journal, v. 44, n. 7, p. 1079-1088, 2016. DOI:

https://doi.org/10.2224/sbp.2016.44.7.1079.

KOTLER, P.; KELLER, K. L. Administração de Marketing. 12. ed. São Paulo: Pearson Education do Brasil Ltda, 2006.

KOTLER, P.; ZALTMAN, G. Social marketing: an approach to planned social change. The Journal of Marketing, v. 35, n. 3, p. 3-12, 1971.

LABOISSIÈRE, P. OMS alerta para impacto do cigarro na saúde cardiovascular. AGÊNCIA BRASIL. Saúde. 31/05/2018. Disponível em: http://agenciabrasil.ebc.com.br/saude/noticia/201805/oms-alerta-para-impacto-do-cigarro-na-saude-cardiovascular. Acesso em: 21 nov. 2018.

LASKOSKI, L. M.; NATIVIDADE, J. C.; HUTZ, C. S. Development of Instruments to Assess Shame and Guilt in Adolescents: Empirical Differences Between the Constructs. Paidéia, v. 23, n. 55, p. 171-178, 2013.

LATOUR, M. S.; SNIPES, R. L.; BLISS, S. J. Don't be afraid to use fear appeals: An experimental study. Journal of Advertising Research, v. 36, n. 2, p. 59-68, 1996.

LIMA, L. I. D. Relação entre foco regulatório e tipo de premiação sobre a percepção de sacrifícios em programas de lealdade. 2012. 132f. Tese (Doutorado em Administração). Programa de PósGraduação em Administração, Setor de Ciências Sociais Aplicadas, Universidade Federal do Paraná. Curitiba: UFPR.

LINDSTROM, M. Neuromarketing, attività cerebrale e comportamenti d'acquisto. Roma: Apogeo Gruppo Giacomo Feltrinelli Editore, 2009.

LOCKWOOD, P.; JORDAN, C. H.; KUNDA, Z. Motivation by positive or negative role models: regulatory focus determines who will best inspire us. Journal of personality and social psychology, v. 83, n. 4, p. 854-864, 2002.

MALHOTRA, N. Pesquisa de Marketing: uma orientação aplicada. 4. ed. Porto Alegre: Bookman, 2006.

MAYER, V. F.; AVILA, M. G. A influência da estruturação da mensagem em comportamentos relacionados à saúde: um teste experimental. Saúde e Sociedade, v. 19, n. 3, p. 685-697, 2010.

MOTA, J. R.; ACEVEDO, C. R.; PRADO, R. A. D. P.; CUNHA, J. A. C.; SILVA, M. A. Impacto do apelo ao medo nas embalagens do cigarro: a percepção de fumantes em relação às mensagens de advertência antitabagismo. Revista Eletrônica de Ciência Administrativa, v. 12, n. 2, p. 246-259, 2013.

NEVES, M. Marketing social no Brasil: a nova abordagem na era da gestão empresarial globalizada. Rio de Janeiro: E-papers, 2001.

OSAF. Benefícios das atividades físicas na terceira idade. 2012. Disponível em: http://osaf.com.br/osaf2/?p=604. Acesso em: 5 out.2015.

PALLANT, J. SPSS Survival Manual. Philadelphia: Open University Press, 2001. 
PHAM, M. T.; HIGGINS, E. T. Promotion and Prevention in Consumer Decision-Making: The State of the Art and Theoretical Propositions. In: RATNESHWAR, S.; MICK, D. G. (ed) Inside Consumption: Consumer Motives, Goals, and Desires. Abingdon, Oxon: Routledge, 2005, p. 8-43.

ROTHMAN, A. et al. The strategic use of gain- and loss-framed messages to promote healthy behavior: how theory can inform practice. Journal of Communication, v. 56, n. 1, p. 202-220, 2006.

SANCHEZ, Z. V. M.; NAPPO, S. A. Sequência de drogas consumidas por usuários de crack e fatores interferentes. Revista Saúde Pública, v. 36, n. 4, p. 420-430, 2002.

SIGNORELLI, N. Mass media images and impact on health: a source book. Westport: Greenwood Press, 1993.

SHADISH, W.R.; COOK, T.D.; CAMPBELL, D.T. Experimental and Quasi-Experimental Designs for Generalized Causal Inference. New York: Houghton Mifflin Company, 2002.

SILVA, J. G.; LOPES, E.L. Pesquisa Científica da Área de Marketing no Brasil: Um Estudo Bibliométrico dos Anais dos Encontros de Marketing da ANPAD. In: Encontro de Marketing da ANPAD, 7, 2016. Anais... Belo Horizonte: ANPAD, 2016.

SILVA, L. C. C. Tabagismo: Doença que tem tratamento. Porto Alegre: Artmed Editora, 2012.

SOAMES JOB, R. F. Effective and ineffective use of fear in health promotion campaigns. American journal of public health, v. 78, n. 2, p. 163-167, 1988.

TVERSKY, A.; KAHNEMAN, D. The framing of decisions and the psychology of choice. Science Magazine, v. 211, n. 4481, p. 443-458, 1981.

UNESP. Sobre o fique sem fumar: fumantes usam a nicotina para controlar suas emoções. Projeto Viver Bem. Livreto 1: uma visão geral. 2012. Disponível em:

http://www.fmb.unesp.br/\#!/departamentos/neurologia-psicologia-e-psiquiatria/projetos/viverbem/tabaco/livreto-1-uma-visao-geral/. Acesso em: 16 jun. 2014.

WITTE, K.; ALLEN, M. A meta-analysis of fear appeals: Implications for effective public health campaigns. Health education \& behavior, v. 27, n. 5, p. 591-615, 2000. 